\title{
INTERSECÇÕES ENTRE DESIGN THINKINGS E FORMAÇÃO DE PROFESSORES
}

\author{
Andreia de Bem Machado ${ }^{1}$, Andreza Regina Lopes da Silva ${ }^{2}$ \\ ${ }^{1,2}$ Universidade Federal de Santa Catarina \\ ${ }^{1}$ andreiadebem@gmail. com \\ 2 andrezalopes . ead@gmail.com
}

\section{Resumo}

A inovação é elemento integrado à sociedade contemporânea com novas metodologias no fazer pedagógico. A formação do docente amplia-se para uma visão integral do homem que promovendo novas metodologias para o ensino com intersecções de ferramentas diversas. Essas inovações metodoogicas fazem parte de um novo cenário educacional, onde o estudante é mais participativo e autonomo no seu pensar. Isso faz com que o professor procure por um novo fazer pedagógico inserindo nesse planejamento e problámticas que permitam com que o estudante motivesse a aprender. Esse faz com que a sala de aula torne-se um espaço de interação e de problematizações que tenha como pano de fundo as ferramentas do desinger thinking. Esse é utilizado para elaboração das aulas e também para oportunizar novas maneiras de ensinar ao estudantes dessa sociedade do conhecimento. Sendo assim, o objetivo nesse artigo é mapear as intersecções entre design thinking e a formação de professores. Para tanto se realizou uma busca sistemática seguida de uma análise bibliométrica na base de dados Scopus. Como resultado, identificou-se que a pesquisa emerge no campo das Ciências Socias intersectando as discussões na área de Engenharia; Ciência da Computação; Ciência ambiental; Artes e Humanidades; Negócios, Gestão e Contabilidade; Ciências da decisão e Medicina e congrega um novo olhar ao fazer pegagócio trazendo então uma discussão que transcenda a modelos cartezianos de ensinar onde aprendizagem se concebia em um processo passivo.

Palavras Chave: Design thinking. Professor. Ensino.

\section{INTERSECTIONS BETWEEN DESIGN THINKINGS AND TEACHER TRAINING}

\begin{abstract}
Innovation is an integrated element to contemporary society with new methodologies in pedagogical doing. The training of the teacher expands to an integral vision of the man that promoting new methodologies for the teaching with intersections of diverse tools. These methodological innovations are part of a new educational scenario, where the student is more participatory and autonomous in his thinking. This causes the teacher to look for a new pedagogical practice, inserting in this planning and problamticas that allow the student to motivate to learn. This makes the classroom become a space of interaction and problematizations that has as a background the tools of desinger thinking. This is used to prepare classes and also to provide new ways of teaching students of this knowledge society. Thus, the objective in this article is to map the intersections between design thinking and teacher training. A systematic search was carried out followed by a bibliometric analysis in the Scopus database. As a result, it was identified that the research emerges in the field of Socio Sciences intersecting the discussions in the Engineering area; Computer science; Environmental science; Arts and Humanities; Business, Management and Accounting; Decision Science and Medicine and congregates um novo olhar ao fazer pegagócio trazendo R. Eletr. do Alto Vale do Itajaí - REAVI, v. 6, n. 9, p. 77-86, jul., 2017 ISSN: 2316-4190, DOI: 10.5965/2316419006092017077
\end{abstract}


então uma discussão that transcends to cartezianos models of ensiling on aprendizagem was conceived em a passive process.

Keywords: Design thinking. Teacher. Teaching.

\section{Introdução}

Ao longo da história nota-se que as formações dos profissionais para as mais variadas áreas foram pautadas em metodologias tradicionais, influenciadas por modelos fragmentados, que compartimentam o conhecimento em campos altamente especializados. Isso tornou-se visível nas universidades subdividido o conhecimento em departamentos, áreas, campos e os cursos em períodos modelados por disciplinas estagnadas. Sendo assim, o processo de ensinoaprendizagem, dentro desse contexto desenvolve-se com base na repetição do conhecimento. Dentro desse cenário o docente passa a ser um transmissor de conteúdos e o estudante um repetidor dos conteúdos, assumindo uma postura passiva e reprodutora, sem refletir criticamente o conteúdo temático abordado pelo professor.

No contexto atual, em meio as tecnologias inovadoras atreladas aos meios de comunicação, o ser humano vive em um mundo interconectado por redes de relações dinâmicas e fluidas o que exige a necessidade de mudanças nas instituições de ensino. $\mathrm{Na}$ formação de profissionais para as diversos campos do conhecimento, surge as discussões referentes ao processo de ensino-aprendizado visando a formação do profissional com competências e habilidades para desenvolvimento integral do indivíduo. Para legitimar essas inquietações surgem na Lei de diretrizes e bases da Educação Nacional (LDB) com ações voltadas a conhecimentos e práxis do contexto do estudante. Exigindo uma escola voltada a um serviço especializado à população, estabelecendo com ela uma relação de reciprocidade (BRASIL, 2009). Assim, as instituições de ensino tiveram que passar por mudanças em suas práticas pedagógicas na tentativa de aproximarem-se as demandas da realidade social e também motivando docentes e discentes a articular novas redes de conhecimento.

Imersos nessa rede de conhecimento temos metodologias de ensino que são a formação do profissional nas mais diferentes áreas discute-se o aprender a conhecer, aprender a fazer, aprender a viver junto e aprender a ser uma preocupação já apresentada a Unesco como resultante de um Congresso Internacional de Educação coordenado por Jacques Delores. Nesse cenário surge as metodologias ativas como proposta no princípio inovação teórico freiriano (Referente a Paulo Freire, educador brasileiro, que tinha proposta pedagógica a pedagógica libertadora). Nessa proposta a educação deve pressupor um estudante autônomo, que auto gerencie autogoverne seu processo formativo buscando continuamente a construção do conhecimento que por sua vez

[...] pressupõe um sujeito ativo, que participa de maneira intensa e reflexiva dos processos educativos. Um sujeito que constrói sua inteligência, sua identidade e produz conhecimento através do diálogo estabelecido com seus pares, com os professores e com a cultura, na própria realidade cotidiana do mundo em que vive. Refiro-me, portanto, a alunos que são autores do conhecimento, e não meros reprodutores daquilo que já foi produzido. (ARAÙJO, 2011, p. 41)

Segundo Cyrino e Toralles-Pereira (2004) as metodologias ativas utilizam a problematização para motivar e aproximar o aluno mediante a um problema apresentado para que ele seja capaz de relacionar as suas descobertas para a resolução da problemática proposta. Considera-se que mediante a problematização o estudante reflete de forma crítica produzindo novos conhecimento motivado por solucionar dúvidas e inquietações referente aos 
problemas promovendo novos aprendizados. De acordo com Deelman e Hoeberigs (2009, p. 82)

Aprendizagem ativa significa que aprender é um processo ao longo do qual os conhecimentos são construídos de maneira ativa, o que representa o outro extremo de receber conhecimentos passivamente, mediante instrução. Esta deveria apenas facilitar atividades construtivas do aluno.

Nesse contexto de aprendizagem ativa temos as tecnologias inovadoras atreladas aos meios de comunicação que tem influenciado o uso de novas ferramentas no fazer pedagógico, trazendo processos inovadores. Uma das ferramentas que têm demostrado eficácia na busca por inovação no processo de ensino adotado pelos professores é o design thinking. Segundo Vianna et al. (2012), o design thinking está atrelado à forma de ver as coisas e resolver os problemas, pois utiliza-se de um tipo de raciocínio pouco convencional no meio acadêmico, o pensamento abdutivo, que é um processo participativo para formar hipóteses explicativas. Os autores destacam que "é pensando de maneira abdutiva que o designer constantemente desafia seus padrões, fazendo e desfazendo conjecturas, e transformando-as em oportunidades para a inovação" (VIANNA et al., 2012, p. 14).

Com base nessa contextualização, o objetivo deste estudo é mapear as intersecções entre design thinking e formação de professores com vistas a ampliar a reflexão para uma atuação docente que transcenda a modelos cartezianos de ensinar onde a aprendizagem se concebia em um processo passivo. Para tanto, o artigo está planejado em cinco seções. A primeira, anteriormente explicitada, intitula-se "Introdução". Na segunda seção, apresentamse os procedimentos da pesquisa. Na terceira seção, mostra-se de modo detalhado o resultado bibliométrico de pesquisa, baseado no cenário das publicações científicas da área. Na quarta seção, são explicitadas as considerações finais. Por último, na quinta seção, elencam-se as referências utilizadas.

\section{Caminho metodológico}

Para atender à problemática da pesquisa deste estudo, trabalhou-se a partir da metodologia exploratório-descritiva, com o objetivo de delinear o tema e aumentar a familiaridade dos pesquisadores com o fato, contribuindo para ampliar os conceitos inerentes ao tema em estudo (MARCONI; LAKATOS, 2010).

Como método de pesquisa da literatura, utilizou-se a busca sistemática em uma base de dados on-line, seguida de uma análise bibliométrica dos resultados. A bibliometria é uma metodologia oriunda das ciências da informação que, com base em análise quantitativa, permite mapear publicações a partir de registros bibliográficos armazenados em bases de dados (FEATHER; STURGES, 2003; SANTOS; KOBASHI, 2009). Desse modo, considerase que a proposta metodológica definida atende à problemática de pesquisa, orientando a construção de um estudo que esteja alinhado com o seu objetivo geral.

Para a análise bibliométrica, o estudo foi elaborado em três etapas distintas: planejamento, coleta de dados e análise de resultados. Essas etapas aconteceram de modo integrado e síncrono para responder à pergunta norteadora da pesquisa: Quais intersecções emergem da combinação entre design thinking e formação de professores?

O planejamento iniciou-se no mês de julho de 2017, quando a pesquisa foi efetivada. No escopo do planejamento, foi estipulada como relevante para o domínio da pesquisa a base de dados Scopus ( $<$ http://www.scopus.com $>$ ), devido a sua importância no meio acadêmico, seu caráter interdisciplinar, sua atualidade e também por ser uma das maiores bases de resumos e referências bibliográficas de literatura científica revisada por pares. 
Considerando-se o problema de pesquisa, delimitaram-se os termos de busca no início da fase 2 - coleta de dados -, e eles foram definidos como " 'design thinking' and teacher". Como princípio básico para a busca, optou-se pela utilização dos termos nos campos "Title", "Abstract" e "Keyword", sem restrição temporal, de idioma ou outra qualquer que possa limitar o resultado. Essa fase recuperou um total de 32 trabalhos indexados, com o primeiro registro datado de 2010 e o último de 2016.

$\mathrm{Na}$ terceira fase, de análise de resultados, identificou-se que os trabalhos foram escritos por 78 autores, vinculados a 37 instituições. Foram utilizadas 203 palavras-chave para identificar e indexar as publicações, que se apresentam distribuídas em oito áreas do conhecimento. O quadro 1 apresenta o resultado da coleta de dados numa análise bibliométrica geral dos resultados obtidos na base de dados Scopus.

Quadro 1 - Bibliometria da intersecção entre design thinking e formação de professores

\begin{tabular}{|l|l|}
\hline Base de dados & Scopus \\
\hline Termos de busca & “design thinking” and teacher \\
\hline Campos de busca & Title, Abstract, Keyword \\
\hline Total de trabalhos recuperados & 32 \\
\hline Autores & 78 \\
\hline Instituições & 37 \\
\hline Países & 16 \\
\hline Palavras-chave & 203 \\
\hline Áreas do conhecimento & 8 \\
\hline
\end{tabular}

Fonte: Elaborado pelas autoras (2017).

O universo de 32 trabalhos científicos corresponde a artigos que compuseram a amostra da análise bibliométrica das publicações. As áreas compreendidas são: Ciências Sociais; Engenharia; Ciência da Computação; Ciência Ambiental; Artes e Humanidades; Negócios, Gestão e Contabilidade; Ciências da Decisão; Medicina. Os trabalhos foram publicados entre 2010 e 2016, o que permite tecer o estado da arte do tema a partir da base de dados consultada.

Para a apreciação dos resultados de maneira mais aprofundada na análise bibliométrica, fez-se a exportação dos dados para um software de gerenciamento bibliográfico denominado EndNoteWeb. Na sequência, organizou-se uma planilha de dados eletrônica com as informações definidas como relevantes para o estudo: distribuição temporal; principais autores, instituições e países; tipo de publicação na área; principais palavras-chave; trabalhos mais referenciados.

\section{Apresentação de dados e discussões}

Inicialmente, analisou-se a distribuição temporal dos trabalhos, o que permitiu identificar que a primeira publicação está datada de 2010, com um artigo nesse ano. Já em 2011, teve-se um aumento de ocorrências, com a publicação de dois artigos. Em 2012, foram publicados três trabalhos e, em 2013, cinco artigos. Em 2014, houve uma diminuição no 
número de artigos; quatro foram publicados. No ano seguinte, em 2015, ocorreu um aumento considerável: foram publicados dez artigos. Em 2016, houve um decréscimo novamente, com a publicação de sete artigos. Essa frequência mostra a descontinuidade e a carência de pesquisas na área. Para melhor visualizar esses dados, elaborou-se o gráfico 1.

Gráfico 1 - Distribuição dos trabalhos publicados por ano

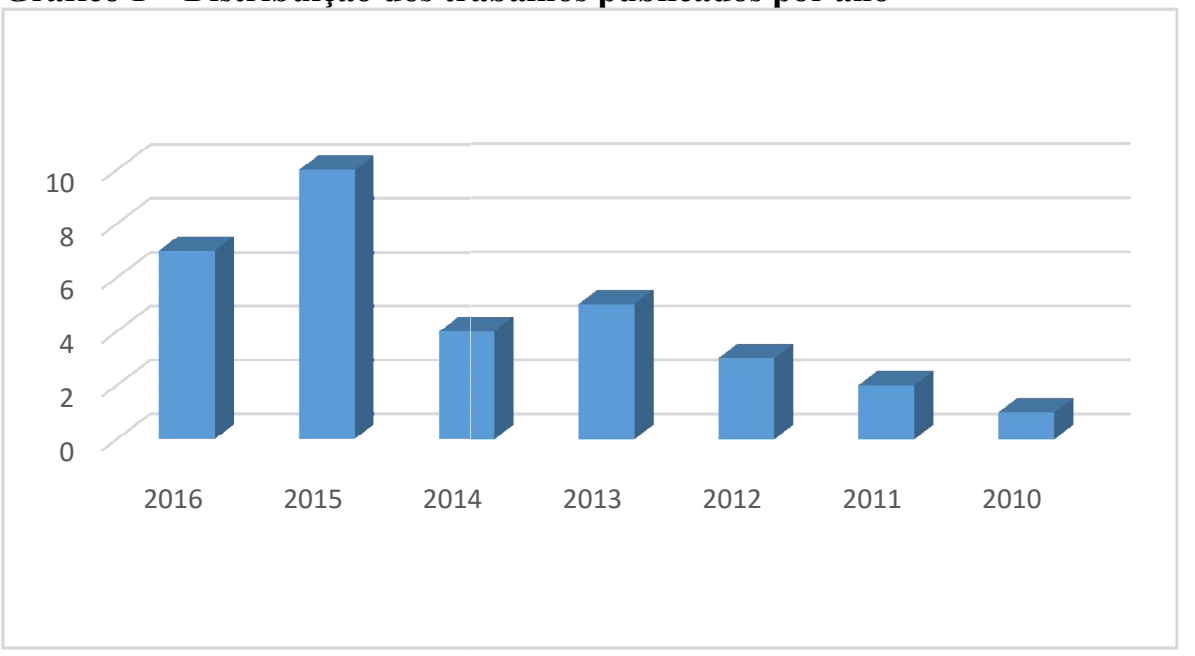

Fonte: Elaborado pelas autoras (2017).

Percebe-se que as pesquisas na área podem ser consideradas incipientes, pois segundo análise quantitativa, apresentam-se em pequena proporção. Infere-se, a partir desse olhar, a necessidade de ampliação das pesquisas relacionadas à temática "design thinking na formação de professores", para que seja possível a exploração de novas metodologias de ensino, as quais permitam a formação de indivíduos críticos que integrem a sociedade contemporânea uma sociedade do conhecimento. Seguindo-se essa análise, destacam-se no último ano, 2016, sete pesquisas indexadas, como apresentado no quadro 2.

Quadro 2 - Ocorrências de design thinking na base de dados Scopus em 2016

\begin{tabular}{|c|c|c|}
\hline Autor & $\begin{array}{l}\text { Título original } \\
\text { do artigo }\end{array}$ & Resumo do artigo \\
\hline $\begin{array}{l}\text { Kriek, Jeanne; } \\
\text { Coetzee, Annaretha }\end{array}$ & $\begin{array}{l}\text { Development of a } \\
\text { technology integrated } \\
\text { intervention in tertiary } \\
\text { education }\end{array}$ & $\begin{array}{l}\text { Fornece ferramentas de apoio aos professores } \\
\text { que permitem uma intervenção integrada em } \\
\text { tecnologia, avaliada na disciplina de } \\
\text { mecânica de fluidos. Assim, pode-se apoiar o } \\
\text { aprendizado do século XXI de estudantes de } \\
\text { Física do primeiro ano. }\end{array}$ \\
\hline $\begin{array}{l}\text { Clemente, Violeta; } \\
\text { Tschimmel, Katja; } \\
\text { Vieira, Rui Marques }\end{array}$ & $\begin{array}{l}\text { Creative and critical } \\
\text { thinking in product } \\
\text { development: an } \\
\text { educational initiative } \\
\text { based on design } \\
\text { thinking }\end{array}$ & $\begin{array}{l}\text { Apresenta informações sobre um estudo de } \\
\text { caso que trata da aplicação do modelo de } \\
\text { design thinking. Traz um projeto de uma } \\
\text { iniciativa educacional voltada à promoção do } \\
\text { pensamento criativo e crítico no ensino } \\
\text { superior. }\end{array}$ \\
\hline Retna, Kala S. & $\begin{array}{l}\text { Thinking about } \\
\text { "design thinking": a } \\
\text { study of teacher } \\
\text { experiences }\end{array}$ & $\begin{array}{l}\text { Analisa percepções, experiências e desafios } \\
\text { do professor na adoção do design thinking. A } \\
\text { pesquisa também destaca vários desafios da } \\
\text { aplicação do modelo, como recursos } \\
\text { inadequados, restrições de tempo, medo de } \\
\text { notas precárias e dificuldade de mudar para } \\
\text { uma nova maneira de ensinar e aprender, a }\end{array}$ \\
\hline
\end{tabular}




\begin{tabular}{|l|l|l|}
\hline & & $\begin{array}{l}\text { qual se difere muito da abordagem } \\
\text { tradicional. }\end{array}$ \\
\hline Leonard, Simon N. & $\begin{array}{l}\text { Using developmental } \\
\text { evaluation as a design } \\
\text { thinking tool for } \\
\text { curriculum innovation } \\
\text { in professional higher } \\
\text { education }\end{array}$ & $\begin{array}{l}\text { Discute o uso da avaliação do } \\
\text { desenvolvimento como uma ferramenta de } \\
\text { pesquisa baseada em design para a inovação } \\
\text { curricular sustentável no ensino superior } \\
\text { profissional. }\end{array}$ \\
\hline Jordan, Michelle E. & $\begin{array}{l}\text { Teaching as } \\
\text { designing: preparing } \\
\text { pre-service teachers } \\
\text { for adaptive teaching }\end{array}$ & $\begin{array}{l}\text { Explicita o conceito de design atrelado ao } \\
\text { ensino argumentando que uma ação crítica } \\
\text { que os professores realizam é projetar } \\
\text { sistemas que permitam que seus alunos } \\
\text { aprendam. }\end{array}$ \\
\hline $\begin{array}{l}\text { Araújo, Ulisses F.; } \\
\text { Arantes, Valéria }\end{array}$ & $\begin{array}{l}\text { Principles and } \\
\text { methods to guide } \\
\text { education for purpose: } \\
\text { Danza, Hanna Cebel; } \\
\text { Pinheiro, Viviane } \\
\text { Potenza Guimarães; } ; \\
\text { Garbin, Monicarience }\end{array}$ & $\begin{array}{l}\text { Apresenta uma experiência brasileira na } \\
\text { pedagogias inovadoras, como aprendizagem } \\
\text { baseada em problemas e aprendizagem } \\
\text { baseada em projetos e design. Os autores } \\
\text { descrevem as etapas que os professores } \\
\text { devem seguir no desenvolvimento de um } \\
\text { projeto. }\end{array}$ \\
\hline $\begin{array}{l}\text { Joyce Hwee Ling, } \\
\text { Koh }\end{array}$ & $\begin{array}{l}\text { Sebate o desenvolvimento e as as design frames } \\
\text { that teachers use when } \\
\text { considering } \\
\text { technological, } \\
\text { pedagogical content } \\
\text { knowledge }\end{array}$ & $\begin{array}{l}\text { implementações de um projeto conduzido por } \\
\text { 27 professores em Cingapura, o qual adotou } \\
\text { sete quadros de design para articular o } \\
\text { conhecimento de conteúdo pedagógico com o } \\
\text { desenho de lições da tecnologia da } \\
\text { informação e comunicação. }\end{array}$ \\
\hline
\end{tabular}

Fonte: Elaborado pelas autoras (2017).

Observa-se, no quadro 2, que o design thinking na formação dos professores está intersectado com o processo de ensino, contribuindo para a construção e reconstrução significativas de novos conhecimentos. Os artigos publicados também explicitam abordagens pedagógicas adequadas e ferramentas para melhorar o ensino que inovam a aprendizagem dos alunos, como a aprendizagem baseada em problemas e a aprendizagem baseada em projetos. Estas são detalhadas, respectivamente, nos artigos "Thinking about 'design thinking': a study of teacher experiences" e "Seven design frames that teachers use when considering technological, pedagogical content knowledge".

A partir de um olhar sistêmico e direcionado aos 32 trabalhos localizados, verifica-se uma variada lista de países que se destacam. Os Estados Unidos são o país com maior destaque, com 19\% das publicações totais, ou seja, sete artigos. Em segundo lugar, tem-se a Austrália, com 15\% das ocorrências, ou cinco trabalhos. Em terceiro lugar, estão Cingapura e Taiwan, com $11 \%$, ou seja, quatro artigos. Em quarto lugar, está a Nova Zelândia, com 8\%, ou três trabalhos publicados. O Brasil aparece em quinto lugar, com 5\% das publicações totais, ou seja, dois artigos, o que permite evidenciar-se que há uma carência de trabalhos nessa área no cenário nacional. $\mathrm{O}$ gráfico 2 demonstra a relação entre países e publicações indexadas na área segundo a base de dados Scopus. 


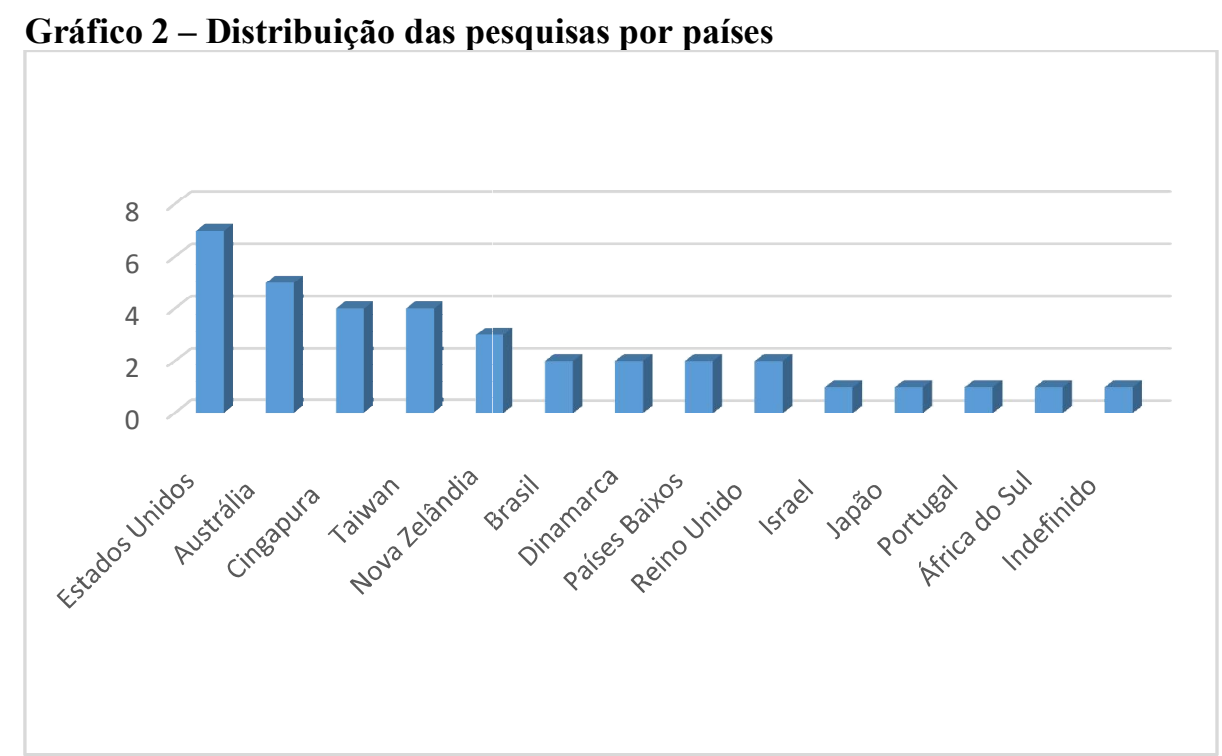

Fonte: Elaborado pelas autoras (2017).

Outra análise quantitativa realizada a partir de um olhar bibliométrico está relacionada ao número de autores que aparecem no resultado da busca. A pequena quantidade de pesquisadores permite afirmar que não existem destaques na área, mas que ela ainda está em construção e desenvolvimento e que os especialistas que nela atuam apresentam-se em número variado de acordo com o país de origem. No quadro 3, organizaram-se os principais autores da área, ou seja, aqueles com no mínimo duas publicações, conforme indexação na base de dados Scopus.

Quadro 3 - Autores com maior número de publicações na área

\begin{tabular}{|c|c|c|c|}
\hline Autor & $\begin{array}{c}\text { Quantidade de } \\
\text { publicações }\end{array}$ & Afiliação & País \\
\hline Chai, Ching Sing & 4 & Instituto Nacional de Educação & Cingapura \\
\hline Koh, Joyce & 3 & Instituto Nacional de Educação & Cingapura \\
\hline Bower, Matt & 2 & Universidade Macquarie & Austrália \\
\hline Eames, Chris W. & 2 & Universidade Tecnológica & Nova Zelândia \\
\hline Hong, Huang- & 2 & Universidade Nacional Chengchi & Taiwan \\
\hline Yao & 2 & Universidade de Waikato & Nova Zelândia \\
\hline Lebo, Nelson & 2 & Cniversidade Nacional de Taiwan de & Taiwan \\
\hline Tsai, Chinchung & & Ciência e Tecnologia & \\
\hline
\end{tabular}

Fonte: Elaborado pelas autoras (2017). 
O quadro 3 apresenta também o número de publicações, a universidade de origem e o respectivo país e, assim, pode-se observar que, dos sete autores que se destacam com discussões e publicações sobre a temática, aqueles que somam mais trabalhos publicados são da Instituto Nacional de Educação, em Cingapura.

Segundo o levantamento geral, foi possível analisar-se ainda as áreas de concentração dos artigos, que se situam nos seguintes campos do conhecimento: Ciências Sociais; Engenharia; Ciência da Computação; Ciência Ambiental; Artes e Humanidades; Negócios, Gestão e Contabilidade; Ciências da Decisão; Medicina, conforme ilustra o gráfico 3.

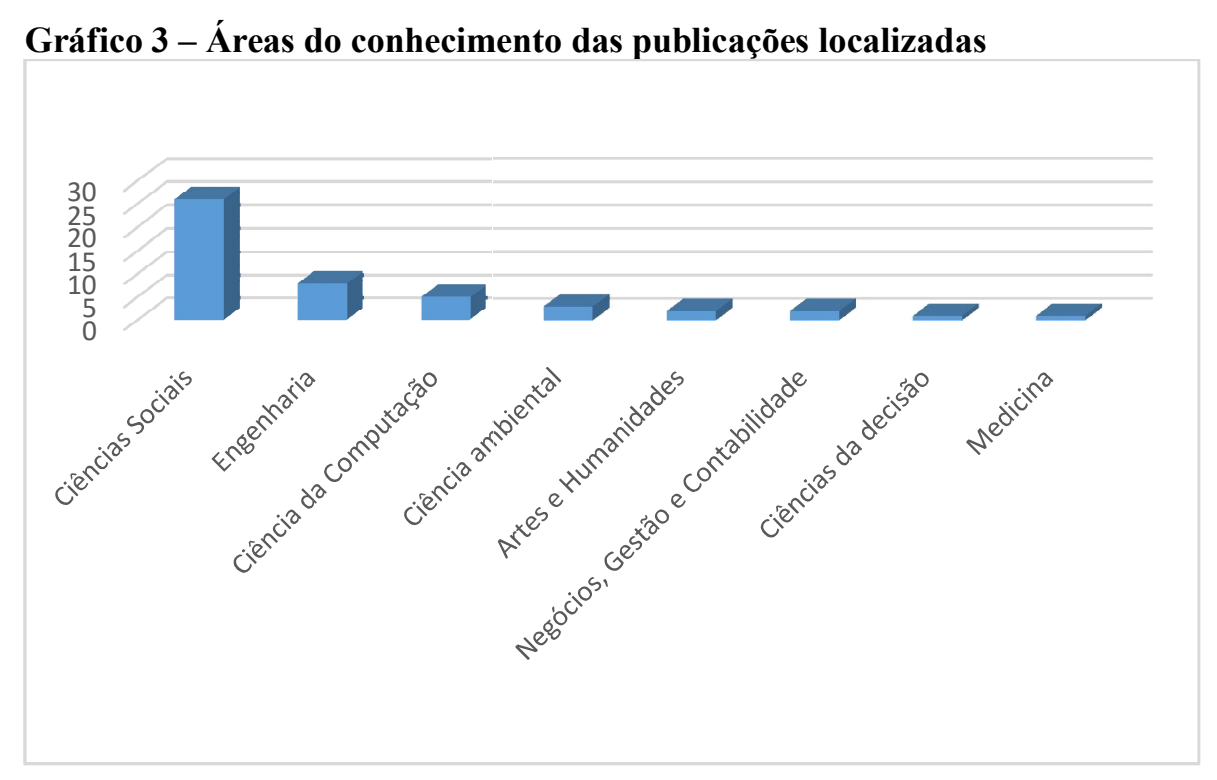

Fonte: Elaborado pelas autoras (2017).

Verifica-se que a maior concentração de publicações está na área de Ciências Sociais, com 54\% dos trabalhos, seguida da área de Engenharia, com 17\%, e de Ciência da Computação, com $11 \%$.

Outra análise realizada a partir da análise bibliométrica, com base no grupo de trabalhos recuperados na base de dados Scopus, foram as palavras-chave adotadas, as quais se sintetizam em 203 termos. O destaque ficou para "design thinking", com 16 ocorrências. Em seguida, pode-se ver as seguintes palavras-chave (entre parênteses, a quantidade de ocorrências): "currículos" (5), "desenhar" (5), "educação de engenharia" (4), "educação" (3), "estudantes" (3), "conhecimento de conteúdo pedagógico-tecnológico" (3), "educação de professores" (3), “tecnologia” (3), “criatividade” (2), "pensamento crítico" (2), "aprendizagem baseada em design" (2), "pesquisa baseada em design" (2), "alfabetização digital" (2), "ensino superior" (2), "tecnologia da informação e comunicação" (2) e "design de aprendizagem" (2). As demais ocorrências não foram consideradas neste artigo, pois aparecem com frequência considerada baixa: apenas uma vez. Na figura 1, destacam-se as ocorrências mais frequentes das palavras-chave. 
Figura 1 - Palavras-chave que intersectam a pesquisa sobre design thinking e formação de professores

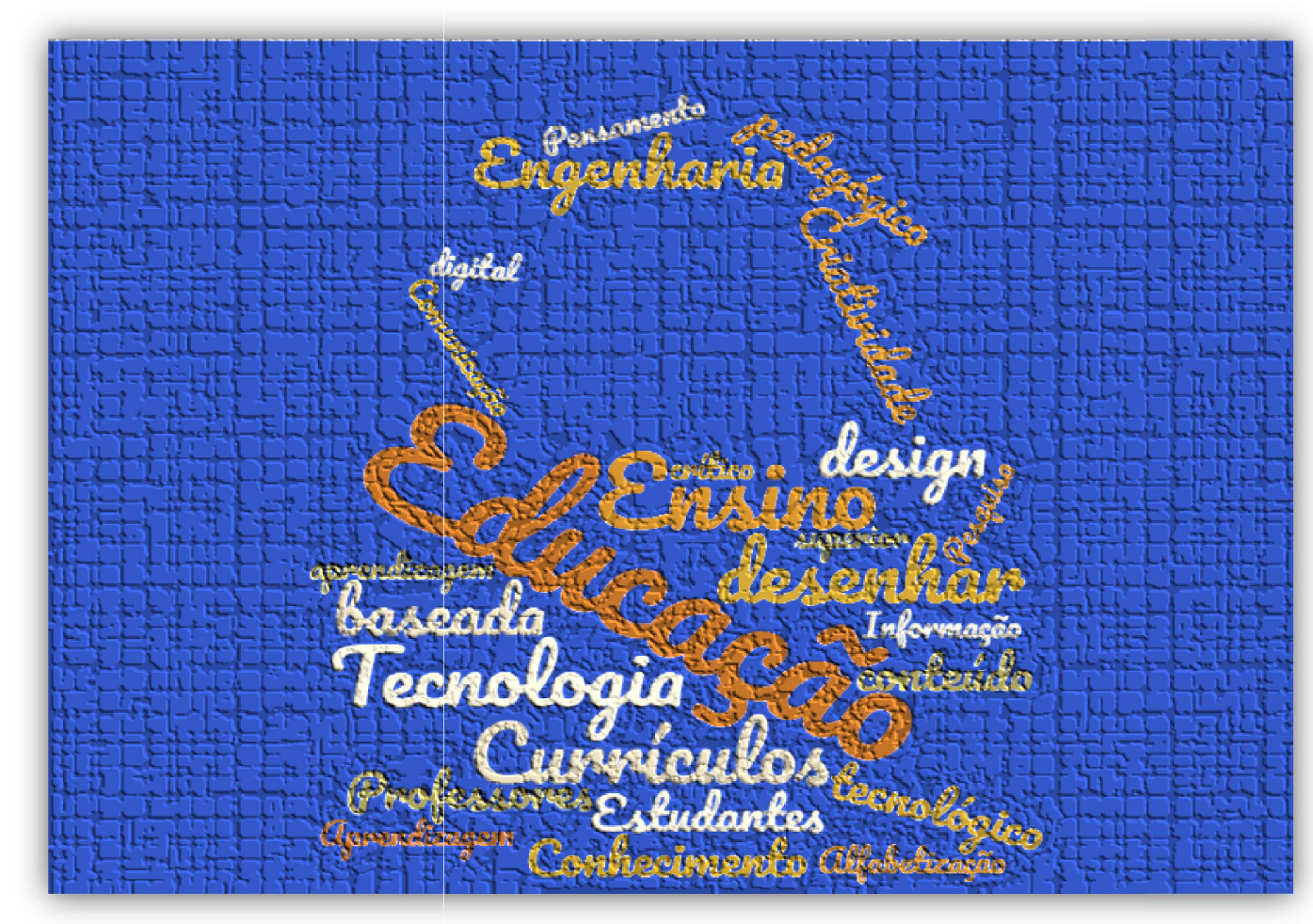

Fonte: Elaborada pelas autoras (2017).

$\mathrm{Na}$ análise das palavras-chave, percebe-se que o debate sobre a intersecção entre design thinking e formação de professores congrega questões relacionadas à educação, com destaque para os temas "currículo", "desenho", "ensino" e "tecnologia". Isso enfatiza uma proposta ativa de construção do conhecimento, caracterizando a exigência de novas metodologias no fazer pedagógico.

Por fim, numa análise de cunho qualitativo, percebeu-se que a discussão envolve ainda a preocupação com novas metodologias que possam ser utilizadas na formação do professor, trazendo à tona questões como ensinar com a lente do design. Esse fato se constitui numa nova forma de fazer educação que não se limita a conteúdos científicos nem a práticas tradicionais de ensino. Ainda permeiam o debate a evolução das tecnologias de comunicação digital, num processo amplo que envolve aluno, professores, instituição de ensino, família e sociedade.

\section{Considerações finais}

Tratar do tema "design thinking na formação de professores" implica debater aspectos relacionados ao processo didático-pedagógico de ensinar e aprender, tópicos estes atrelados a ferramentas inovadoras contribuindo com a formação de um sujeito crítico e autônomo. Nesse contexto, identificou-se que a intersecção emerge da busca pela qualidade no atendimento e na prestação de serviços no contexto educaiconal. Além disso, o uso de ferramentas inovadoras no processo de ensino-aprendizagem promove a interação, pois exige que a abordagem seja centrada no aluno e contemple várias estratégias de ensino que adotem a lente 
do design para atender aos diferentes tipos de aprendizagem. O que permite inferir que o design thinking congrega um novo olhar a formação de um novo professor fazendo um movimento em que os dois principais atores deste processo de ensinar e aprender passam a assumir uma postura ativa.

O mapeamento científico da produção relacionada ao tema "design thinking na formação de professores", realizado na base de dados Scopus, permitiu uma análise bibliométrica que descrevesse as principais discussões da contemporaneidade e a interseção entre as áreas. Como resultado, identificou-se que a pesquisa emerge no campo multidisciplinar, intersectando as discussões nos campos de Ciências Sociais; Engenharia; Ciência da Computação; Ciência Ambiental; Artes e Humanidades; Negócios, Gestão e Contabilidade; Ciências da Decisão; Medicina numa preocupação reflexiva de transcender a modelos cartesianos de ensinar e aprender.

Por fim, evidenciou-se que as discussões sobre design thinking na formação dos professores carecem de estudos e compartilhamento de boas práticas já realizadas. Sugere-se, assim, que estudos nas diferentes áreas sejam analisados e ampliados por um olhar integrado no fazer educacional e que sejam intersectados com planejamentos e práticas educacionais, promovendo ações para educação continuada dos docentes.

\section{Referências}

ARAÚJO, U. F. A quarta revolução educacional: a mudança de tempos, espaços e relações na escola a partir do uso de tecnologias e da inclusão social. Educação Temática Digital. v. 12, n 3, Campinas jan./abr. p. 31-48, 2011.

BRASIL. Lei de Diretrizes e Bases da Educação Nacional. Lei 9.394, 20 de dezembro de 1996. 2009.

CYRINO, E. G., TORALLES-PEREIRA, M. L. Trabalhando com estratégias de ensinoaprendizado por descoberta na área da saúde: a problematização e a aprendizagem baseada em problemas. Cad. Saúde Pública, 2004; v. 20, n. 3), p. 780-788.

DEELMAN, A.; HOEBERIGS, B. A ABP no contexto da Universidade de Maastricht. In: ARAÚJO, Ulisses F. SASTRE, Genoveva (Orgs.). Aprendizagem baseada em problemas no ensino superior. $2^{\mathrm{a}}$ ed. São Paulo: Summus, 2009.

FEATHER, J.; STURGES, R. P. International encyclopaedia of information and library science. [s.l.]: [s.n.], 2003.

MARCONI, M. de A.; LAKATOS, E. M. Fundamentos de metodologia científica. São Paulo: Atlas, 2010.

SANTOS, R. N. M.; KOBASHI , N. Y. Bibliometria, cientometria, infometria: conceitos e aplicações. Tendências da Pesquisa Brasileira em Ciência da Informação, Brasília, v. 2, n. 1, p. 155-172, 2009.

VIANNA, M. et al. Design thinking: inovação em negócios. Rio de Janeiro: MJV, 2012. 